\title{
Pathologic Stage IIIA Cutaneous Melanoma AJCC v8
}

National Cancer Institute

\section{Source}

National Cancer Institute. Pathologic Stage IIIA Cutaneous Melanoma A/CC v8. NCI

Thesaurus. Code C137671.

Stage IIIA includes: T1a/b-T2a, N1a or N2a, M0. T1a: Tumor measuring less than 0.8 $\mathrm{mm}$ in thickness. Ulceration status: Without ulceration. $\mathrm{T} 1 \mathrm{~b}$ : Tumor measuring less than $0.8 \mathrm{~mm}$ in thickness with ulceration, or 0.8-1.0 $\mathrm{mm}$ with or without ulceration. T2a: Tumor measuring more than 1.0 and equal to or less than $2.0 \mathrm{~mm}$ in thickness. Ulceration status: Without ulceration. N1a: One clinically occult nodal metastasis (i.e., detected by sentinel lymph node biopsy). Presence of in-transit, satellite, and/or microsatellite metastases: No. N2a: Two or three clinically occult nodal metastases (i.e., detected by sentinel lymph node biopsy). Presence of in-transit, satellite, and/or microsatellite metastases: No. M0: No evidence of distant metastasis. LDH level is not applicable. (AJCC 8th ed.) 